Original Research Paper

\title{
Community of Seaweeds on Cemara Beach East Lombok
}

\author{
Intan Mushlihah ${ }^{1}$, Lalu Japa ${ }^{{ }^{*}}$, I Gde Mertha ${ }^{1}$, Ahmad Raksun ${ }^{1}$ \\ ${ }^{1}$ Program Studi Pendidikan Biologi FKIP Universitas Mataram, Mataram, Indonesia
}

\author{
Article History \\ Received : June $16^{\text {th }}, 2020$ \\ Revised : June $26^{\text {th }}, 2020$ \\ Accepted : June $30^{\text {th }}, 2020$ \\ Published : July 05 ${ }^{\text {th }}, 2020$ \\ *Corresponding Author: \\ Lalu Japa, \\ Program Studi Pendidikan \\ Biologi FKIP Universitas \\ Mataram, J1. Majapahit No. 62 \\ Mataram, Indonesia \\ Email: ljapa@unram.ac.id
}

\begin{abstract}
Seaweeds (macroalgae) are a marine biological resource that have an important role in aquatic ecosystems and for society. The aim of this research was to determine community of seaweeds in Cemara Beach, East Lombok Regency.Data were collected at four observation points using a method of combinationof the line transect and quadrat. Seaweeds community data were analyzed using density parameters, important values, species diversity index, and species evenness index. The similarity percentage between transects was determined based on the Bray-Curtis cluster analysis using biodiversity program-version 2. In Cemara Beach there were 24 species of macroalgae which memberof 3 divisions, 11 orders and 15 families. Chlorophyta was a division with highest number of species. The number of species for Chlorophyta was 14 species, Rhodophyta division was 7 species, and Phaeophyta division 3 species. The species with highest density is Enteromorpha $\mathrm{sp} ., 25.1 \mathrm{clumps} / \mathrm{m}^{2}$. Ulva lactuca is the species with the highest important value (72.69\%). Diversity and evenness index in Cemara Beach seaweed species were 1,868 (medium category) and 0,699 (almost evenly distributed).The results of cluster analysis based on environmental parameters, species similarity and number of clumps of seaweed species, diversity index, and species evenness index indicate that seaweed in Cemara Beach can generally be divided into 2 groups.
\end{abstract}

Keywords: Community; Cemara Beach; Seaweeds.

\section{Pendahuluan}

Indonesia dengan luas perairan laut 5,8 juta $\mathrm{km}^{2}$ merupakan salah satu negara yang memiliki keanekaragaman hayati tertinggi, dimana salah satu keanekaragaman hayatinya ialah makroalga yang berjumlah 782 spesies (Sugiarto dan Polunin, 1981; Mossa, dkk., 1996 dalam Dahuri, 2003). Spesies dari kelas Rhodophyceae (alga merah) menempati urutan terbanyak dari jumlah spesies yang tumbuh di perairan laut Indonesia yaitu sekitar 452 spesies, disusul oleh kelas Chlorophyceae (alga hijau) sekitar 196 spesies dan kelas Phaeophyceae (alga coklat) sekitar 134 spesies (Winarno, 1996 dalam Ate et al., 2017). Makroalga termasuk dalam kelompok alga/ganggang, dimana bagian yang serupa akar, batang, dan daun belum dapat dibedakan secara struktural.

Makroalga atau yang dikenal dengan nama rumput laut merupakan salah satu sumber daya hayati laut yang memiliki nilai ekonomi yang penting. Kandungan polisakarida yang terdapat pada rumput laut, seperti agar-agar, alginat, dan karaginan dapat berfungsi sebagai stabilisator, pengental, pembentuk gel, pengemulsi, pengilat dan pelembap. Karena sifatnya tersebut, maka polisakarida yang dihasilkan rumput laut banyak dimanfaatkan oleh berbagai industri seperti industry makanan, farmasi, kosmetik, tekstil, kulit,cat, pasta gigi dan industri kimia
(Wibowo et al., 2014). Oleh karena itu, di beberapa daerah, rumput laut mulai dibudidayakan, salah satunya di wilayah Nusa Tenggara Barat. Spesies rumput laut yang sudah dibudidayakan antara lain spesies Eucheuma sp. dan Gracilaria sp.

Berdasarkan data Kementerian Kelautan dan Perikanan (KKP) (2014) potensi produksi dan pengembangan rumput laut di Indonesia cukup besar. Pada tahun 2014 produksi rumput laut sebanyak 10,2 juta ton (basah) mengalahkan jumlah produksi komoditas lainnya seperti udang, kerapu, kakap, bandeng, ikan mas, nila, patin dan gurame (Salim dan Ernawati, 2015). Sementara itu, pada tahun 2016 produksi rumput laut mencapai 11,1 juta ton, dan pada bulan Januari-Oktober 2017 produksi rumput laut sekitar 8,2 juta ton (Sari, 2018).

Di samping memiliki nilai ekonomis, makroalga juga memiliki peran penting dalam ekosistem perairan. Dari segi ekologi, komunitas makroalga (rumput laut) berperan sebagai tempat hidup sekaligus tempat pembesaran dan perlindungan bagi jenis-jenis ikan tertentu dan merupakan makanan alami ikan-ikan dan hewan herbivora lainnya. Dan dari segi biologi, makroalga memegang peranan sebagai produsen primer karena kemampuannya untuk berfotosintesis, penghasil bahan organik, dan oksigen di lingkungan perairan (Kasim, 2016). 
Pantai Cemara merupakan kawasan pantai yang terletak di Desa Seriwe, Kecamatan Jerowaru, Kabupaten Lombok Timur. Masyarakat di sekitar Pantai Cemara kebanyakan bermata pencaharian sebagai pembudidaya rumput laut, sehingga sebagian wilayah Pantai Cemara digunakan sebagai tempat budidaya rumput laut. Di samping memiliki sumber daya hayati rumput laut yang dibudidaya, rumput laut yang tumbuh liar di Pantai Cemara juga cukup melimpah.

Mengingat pentingnya peran makroalga dalam ekosistem perairan termasuk bagi masyarakat, dan potensi rumput laut di Pantai Cemara yang cukup besar, maka perlu dilakukan penelitian mengenai "Komunitas Rumput Laut di Pantai Cemara Kabupaten Lombok Timur".

\section{Bahan dan Metode}

\section{Waktu dan Tempat}

Jenis penelitian ini adalah deskriptif eksploratif. Pengambilan data dilakukan di Pantai Cemara, Desa Seriwe, Kecamatan Jerowaru, Kabupaten Lombok Timur pada pertengahan bulan September 2018, yaitu pada saat air laut berada pada surut terendah pada fase bulan mati. Pengambilan data dilakukan pada 4 titik pengamatan (Gambar 1) menggunakan metode yang mengkombinasikan antara transek garis dan kuadrat. Jumlah kuadrat yang digunakan pada setiap transek adalah 5 buah kuadrat masing-masing berukuran $1 \times 1 \mathrm{~m}^{2}$ yang dibagi menjadi 100 kisi berukuran $10 \times 10 \mathrm{~cm}^{2}$. Posisi geografis transek pengamatan disajikan dalam Tabel 1.

Pengambilan data rumput laut dilakukan dengan cara mengamati dan menghitung jumlah individu atau rumpun spesies rumput laut yang ada di dalam setiap kuadrat serta persentase cover (tutupan) rumput laut, dan mencatat jenis substratnya. Sampel rumput laut yang diperoleh dibersihkan dengan air laut lalu dimasukkan ke dalam plastik klip/kantong plastik yang selanjutnya diawetkan dengan formalin 4\% untuk identifikasi lebih lanjut di Laboratorium Biologi, FKIP, Universitas Mataram.

Identifikasi dilakukan dengan mengamati morfologi makroalga dan menyesuaikannya dengan beberapa sumber, yaitu Romimohtarto dan Juwana (2007), Al-Yamani et al. (2014), Jha et al. (2009), Fuhrer et al. (1988), jurnal-jurnal penelitian, serta situs online dengan alamat web http://v3.boldsystems.org/index.php/ dan http://www.algaebase.org/. Data fisika-kimia perairan, seperti suhu, salinitas, dan $\mathrm{pH}$ diukur langsung di lapangan ketika pengambilan sampel.

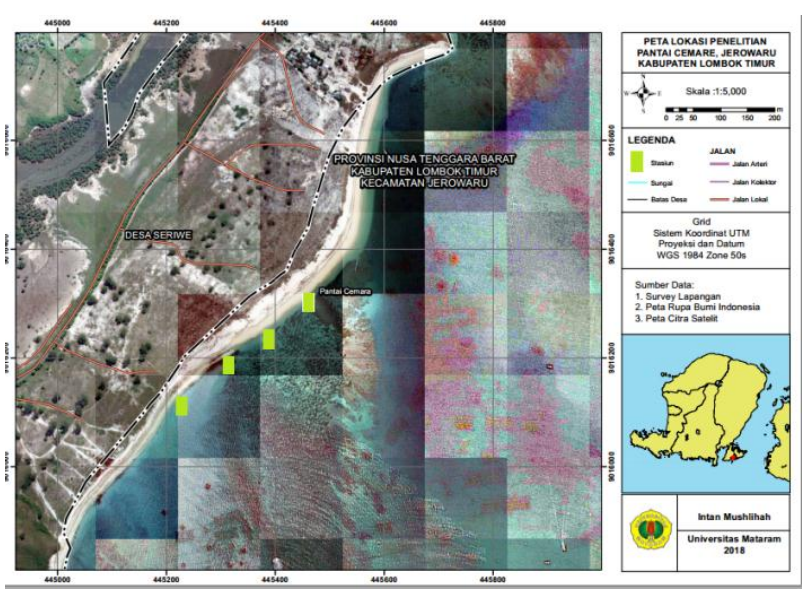

Gambar 1. Lokasi dan Posisi Transek Penelitian di Pantai Cemara, Lombok Timur

Tabel 1. Posisi Geografis Transek Pengamatan

\begin{tabular}{cccc}
\hline \multirow{2}{*}{ No. } & \multirow{2}{*}{ Transek } & \multicolumn{2}{c}{ Posisi Geografis } \\
\cline { 3 - 4 } & & LS & BT \\
\hline 1. & I & $-08^{\circ} 53^{\prime} 55,9^{\prime}{ }^{\prime}$ & $116^{\circ} 30^{\prime} 14,4^{\prime}$, \\
2. & II & $-08^{\circ} 53^{\prime} 58,4^{\prime}$, & $116^{\circ} 30^{\prime} 12,4^{\prime}$ \\
3. & III & $-08^{\circ} 53^{\prime} 59,2^{\prime}$, & $116^{\circ} 30^{\prime} 10,0^{\prime}$, \\
4. & IV & $-08^{\circ} 54^{\prime} 02^{\prime}{ }^{\prime}$ & $116^{\circ} 30^{\prime} 06,3^{\prime}$, \\
\hline
\end{tabular}

Keterangan: LS = Lintang Selatan, BT = Bujur Timur

Data komunitas rumput laut di Pantai Cemara dianalisis dengan perhitungankerapatan, nilai penting, indeks keanekaragaman spesies, indeks kemerataan spesies, serta persentase kesamaan antar transek.

\section{a. Perhitungan Kerapatan}

Data kerapatan makroalga diperoleh dengan menggunakan rumus Brower et al. (1998) dalam Palallo (2013), yaitu:

$$
\mathrm{K}=\frac{n i}{A}
$$

Keterangan:

$\mathrm{K}$ : Kerapatan spesies makroalga (rumpun $/ \mathrm{m}^{2}$ ) ni : Jumlah rumpun setiap spesies makroalga (rumpun)
A : Luas area pengamatan $\left(\mathrm{m}^{2}\right)$

b. Nilai Penting

Nilai Penting (NP) merupakan indeks kepentingan yang menggambarkan pentingnya peranan suatu jenis vegetasi dalam ekosistemnya. Apabila NP suatu jenis vegetasi bernilai tinggi, maka jenis itu sangat mempengaruhi kestabilan ekosistem tersebut. Berikut persamaan untuk mencari nilai penting (Fachrul, 2007):

$$
\mathrm{NP}=\mathrm{FR}+\mathrm{KR}+\mathrm{DR}
$$

$$
\begin{array}{ll}
\text { Keterangan: } \\
\text { NP } & \text { : Nilai Penting } \\
\text { FR } & \text { : Frekuensi Relatif } \\
\text { KR } & \text { : Kerapatan Relatif } \\
\text { DR } & \text { : Dominansi Relatif }
\end{array}
$$


c. Indeks Keanekaragaman Spesies

Indeks keanekaragaman spesies rumput laut dihitung menggunakan rumus Shannon-Wiener (Fachrul, 2007):

$$
H^{\prime}=-\sum \frac{n i}{N} \ln \frac{n i}{N}
$$

Keterangan:

H' : Indeks keanekaragaman Shannon-

Wiener

ni : Jumlah rumpun dari suatu spesies i

$\mathrm{N} \quad$ : Jumlah total rumpun seluruh spesies

d. Indeks Kemerataan Spesies

Indeks kemerataan menunjukkan pola sebaran biota, yaitu merata atau tidak. Rumus yang digunakan adalah rumus dari PIELOU (Romimohtarto dan Juwana, 2007).

$$
\mathrm{E}=\frac{\mathrm{H}^{\prime}}{\ln \mathrm{S}}
$$

Keterangan:

$\begin{array}{ll}\text { E } & \text { : Indeks kemerataan } \\ \text { H' } & \text { : Indeks keanekaragaman Shannon- } \\ & \text { Wiener } \\ \text { S } & \text { : Jumlah spesies }\end{array}$

Perhitungan persentase kesamaan antar transek dilakukan dengan analisis kesamaan BrayCurtiscluster analysis yang selanjutnya disajikan dalam bentuk dendrogram menggunakan Biodiversity Program (BdPro) versi 2.

\section{Hasil dan Pembahasan}

Pengukuran terhadap faktor fisika dan kimia perairan di Pantai Cemara meliputi suhu, salinitas, dan derajat keasaman $(\mathrm{pH})$. Suhu dan salinitas sedikit bervariasi atau relatif sama, sedangkan $\mathrm{pH}$ konstan pada keempat transek pengamatan. Rentangan suhu berkisar antara $27-28^{\circ} \mathrm{C}$, salinitas berkisar antara 32 - 33\%o, dan derajat keasamaan $(\mathrm{pH})$ pada keempat transek sama (7). Jenis substrat pada transek II, III, dan IV relatif sama. Data suhu, salinitas, $\mathrm{pH}$, dan jenis substrat secara rinci disajikan pada Tabel 2.

Tabel 2. Hasil Pengukuran Faktor Fisika-Kimia Perairan dan Jenis Substrat di Pantai Cemara, Desa Seriwe, Kabupaten Lombok Timur Periode September 2018

\begin{tabular}{cccccl}
\hline No. & Transek & $\begin{array}{c}\text { Suhu } \\
\left({ }^{\circ} \mathrm{C}\right)\end{array}$ & $\begin{array}{c}\text { Salinitas } \\
(\%)\end{array}$ & $\mathrm{pH}$ & Jenis Substrat \\
\hline 1. & I & 28 & 33 & 7 & $\begin{array}{l}\text { Berpasir halus } \\
\text { dan terdapat } \\
\text { pecahan karang } \\
\text { Berpasir halus, } \\
\text { terdapat batu }\end{array}$ \\
2. & II & 27 & 33 & 7 & $\begin{array}{l}\text { karang, dan } \\
\text { pecahan karang } \\
\text { Berpasir halus, } \\
\text { terdapat batu }\end{array}$ \\
\hline 3. & III & 27 & 33 & 7 & \\
\hline
\end{tabular}

karang, dan pecahan karang Berpasir halus, terdapat batu karang, dan pecahan karang

Hasil identifikasi rumput laut (makroalga) di Pantai Cemara menunjukkan bahwa terdapat 24 spesies makroalga yang tumbuh liar, yang merupakan anggota dari 3 divisi, yang mencakup 11 ordo dan 15 famili. Empat belas spesies merupakan divisi Chlorophyta, 7 spesies divisi Rhodophyta, dan 3 spesies divisi Phaeophyta.

Jumlah spesies makroalga yang ditemukan di Pantai Cemara hampir sama dengan jumlah spesies yang ditemukan di Pantai Panjang, Kota Bengkulu (Supriati, 2003) dan di daerah intertidal bagian selatan Pulau Lombok (Karnan et al., 2018) yaitu masingmasing sebanyak 22 spesies. Jumlah spesies makroalga di Pantai Cemara lebih banyak dibandingkan 9 spesies makroalga perairan pantai PulauDofamuel Sidangoli, Kabupaten Halmahera Barat (Sinyo dan Somadayo, 2013) dan 12 spesies di perairan Pulau Serangan, Denpasar (Herlinawati et al., 2017). Sebaliknya, jumlah spesies yang ditemukan di Pantai Cemara jumlahnya lebih sedikit dibandingkan dengan jumlah spesies yang ditemukan di daerah intertidal Pantai Senggigi, yaitu sebanyak 89 spesies (Haryati, 2003) dan 61 spesies makroalga di perairan Pantai Sekotong (Sukiman et al., 2014).

Banyaknya jenis makroalga yang ditemukan di Pantai Cemara tentu dipengaruhi oleh kondisi lingkungan yang mendukung dimana suhu perairan Pantai Cemara berkisar antara $27-28^{\circ} \mathrm{C}$. Kisaran suhu tersebut bersifat optimal bagi pertumbuhan makroalga, sebagaimana yang dikemukakan oleh Kuncoro (2004), bahwa bagi pertumbuhan makroalga daerah tropissuhu yang baik berkisar antara $27-30^{\circ} \mathrm{C}$. Salinitas perairan Pantai Cemara berkisar antara 32 33\%. Menurut Luning (1990) dalam Kurniawan (2017), umumnya makroalga hidup di laut dengan salinitas antara 30 - 32\%o, namun banyak juga jenis makroalga yang hidup pada kisaran salinitas yang lebih besar. Berbeda dengan salinitas dan suhu, $\mathrm{pH}$ pada keempat transek pengamatan memiliki nilai yang sama, yaitu 7. Menurut Anggadireja et al. (2006) dalam Ferawati et al. (2014), pH yang optimum untuk pertumbuhan makroalga berkisar antara 6,8 - 8,2.

Jumlah spesies dan jumlah rumpun tiap spesies makroalga berbeda-beda sehingga mempengaruhi jumlah total rumpun pada masing-masing transek penelitian. Persebaran jumlah spesies rumput laut pada keempat transek penelitian tidak jauh berbeda. Pada transek I dan II masing-masing ditemukan 15 spesies makroalga, sedangkan pada transek III dan IV ditemukan masing-masing 14 spesies makroalga.

Spesies makroalga yang ditemukan di Pantai Cemara kebanyakan merupakan anggota dari divisi Chlorophyta, yaitu sebanyak 14 spesies dan divisi 
Pheophyta memiliki jumlah spesies terendah, yaitu hanya 3 spesies. Hasil ini sesuai dengan yang ditemukan di perairan Manokwari oleh Ayhuan et al. (2017), dimana jumlah spesies dari divisiChlorophyta paling dominan, yaitu 14 spesies, lalu disusul divisi Rhodophyta 8 spesies dan divisi Pheophyta 6 spesies.Menurut Ira (2018), tingginya divisi Chlorophyta yang ditemukan disebabkan karena divisi Chlorophyta tumbuh tersebar di perairan pantai sehingga memperoleh intensitas penyinaran matahari yang lebih banyak untuk proses fotosintesis, sebagaimana pernyataan Odum (1993) bahwa secara vertikal, alga kelas Chlorophyceae tersebar di perairan pantai, lebih ke tengah kelas Phaeophyta dan lebih dalam lagi kelas Rhodophyta. Kelas Chlorophyceae memiliki pigmen dominan hijau yang berasal dari klorofil yang dikandung makroalga.Di samping itu, Romimohtarto dan Juwana (2007) menyatakan bahwa sebaran alga hijau (Chlorophyta) terutama terdapat di mintakat litoral bagian atas, khususnya di belahan bawah dari mintakat pasut, dan tepat di daerah bawah pasut sampai kejelukan $10 \mathrm{~m}$ atau lebih, jadi persebarannya di habitat yang mendapat penyinaran matahari bagus. Rendahnya jumlah spesies dari divisi Phaeophyta yang ditemukan kemungkinan disebabkan oleh faktor musim. Sebagaimana yang dinyatakan oleh Soegiarto et al. (1978) dalam Dwimayasanti dan Kurnianto (2018), bahwa sebagian besar makroalga bersifat musiman, sehingga berpengaruh terhadap jumlah spesies yang ditemukan. Jumlah rumpun makroalga tertinggi terdapat pada transek I, yaitu sebanyak 778 rumpun, kemudian diikuti oleh transek III, II, dan IV dengan jumlah rumpun berturut-turut 377, 290, dan 204 rumpun.Adanya perbedaan kerapatan pada transek pengamatan terutama disebabkan karena perbedaan kondisi subtrat. Tingginya jumlah rumpun pada transek I disebabkan karena kondisi substrat yang mendukung bagi pertumbuhan makroalga. Transek I berupa substrat pasir halus dengan pecahan karang dan merupakan daerah padang lamun yang cukup subur dan mengalami kekeringan pada saat surut terendah. Menurut Palallo (2013), tingginya kepadatan makroalga pada ekosistem lamun diduga disebabkan olehkarakteristik keanekaragaman habitat seperti jenis substrat, kedalaman, dan hamparan padang lamun yang cukup luas dan subur yang cocok sebagai tempat hidup makroalga. Substrat berpasir pada ekosistem lamun merupakan habitat yang cocok untuk tempat hidup makroalga khususnya dari kelasChlorophyceae dan Phaeophyceae. Lebih lanjut Nybakken (1992) dalamPalallo (2013)menyatakan bahwa, kedalaman yang lebih dangkal memungkinkan tingginya intensitas cahaya matahari yang masuk ke perairan sehingga mempengaruhi produktivitas makroalga.

Makroalga yang memiliki jumlah rumpun terbanyak adalah Enteromorpha sp. dengan jumlah 502 rumpun dan ditemukan pada seluruh transek pengamatan. Sedangkan makroalga yang memiliki jumlah rumpun paling sedikit dan hanya ditemukan pada satu transek, yaitu Codium spongiosum, Boergesenia forbesii, Laurencia majuscula, dan Hydroclathrus clathratus, dimana masing-masing berjumlah 1 rumpun (Gambar 2). Spesies-spesies tersebut umumnya hanya ditemukan pada substrat batu karang.Tinggi rendahnya jumlah rumpun masing-masing spesies tersebut mempengaruhi kerapatannya.

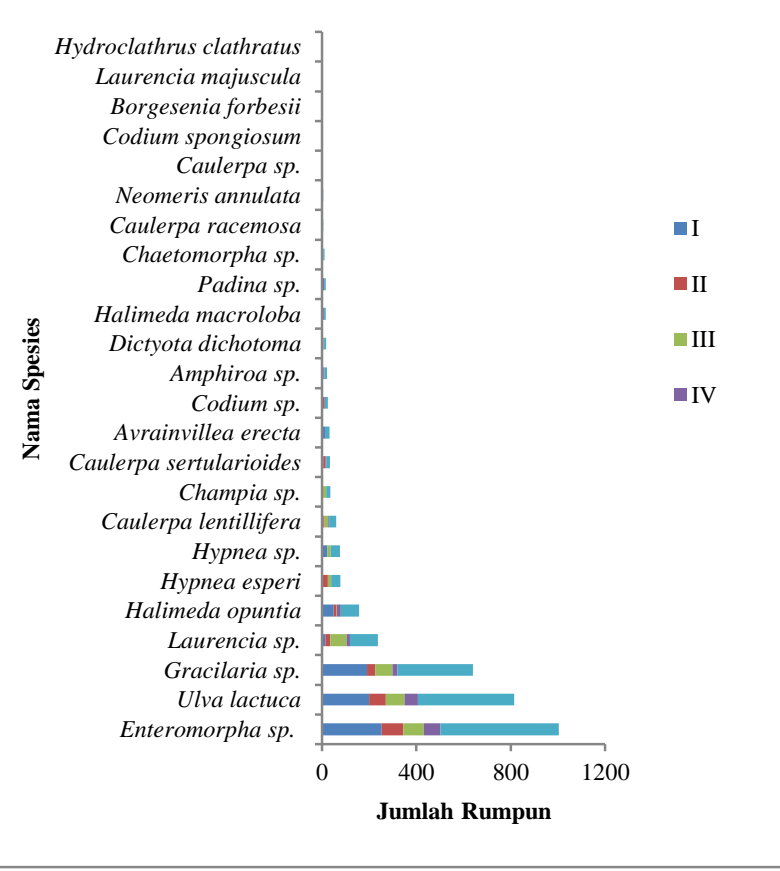

Gambar 2 Proporsi Jumlah Rumpun dan Total Jumlah Rumpun Setiap Spesies Rumput Laut pada Transek Penelitian

Total kerapatan rumput laut di Pantai Cemara adalah 82,45 rumpun $/ \mathrm{m}^{2}$ dengan kerapatan rata-rata 3,44 rumpun $/ \mathrm{m}^{2}$. Dari 24 spesies yang ditemukan, spesies yang memiliki kerapatan tertinggi adalah Enteromorpha sp., yaitu sebanyak 25,1 rumpun $/ \mathrm{m}^{2}$, disusul oleh Ulva lactuca dan Gracilaria sp. dengan kerapatan berturut-turut 20,35 rumpun/ $\mathrm{m}^{2}$ dan 16 rumpun $/ \mathrm{m}^{2}$. Sementara itu, spesies yang memiliki kerapatan terendah adalah Codium spongiosum, Borgesenia forbesii, Laurencia majuscula, dan Hydroclathrus clathratus dengan kerapatan 0,05 rumpun $/ \mathrm{m}^{2} \quad$ (Gambar 3). Jumlah rumpunEnteromorpha sp. paling tinggi dibandingkan spesies lainnya, dan sebaliknya pada Codium spongiosum, Boergesenia forbesii, Laurencia majuscula, dan Hydroclathrus clathratus yang memiliki kerapatan terendah.

Tingginya jumlah rumpun Enteromorpha sp. bisa jadi disebabkan karena disamping kondisi lingkungan perairan yang mendukung, spesies ini juga dapat tumbuh pada berbagai jenis substrat yang ada, sehingga penyebarannya luas. Menurut Borowitzka (1972) dalam Atmadja (2004), Ulva dan Enteromorphamempunyai kemampuan reproduksi yang tinggi. Di samping itu, menurut Zaouali (1983) dalam Luthfi dan Jauhari (2013), pada perairan yang 
mengandung banyak nutrien, Ulva dan Enteromorpha umumnya tumbuh dengan cepat. Menurut Arfah dan Patty (2016) kepadatan suatu organisme ditentukan oleh kemampuannya menyesuaikan diri dengan lingkungan tempat organisme itu hidup, dan adanya dominansi spesies tertentu dimana spesiestersebut menggeser spesies yang lain.

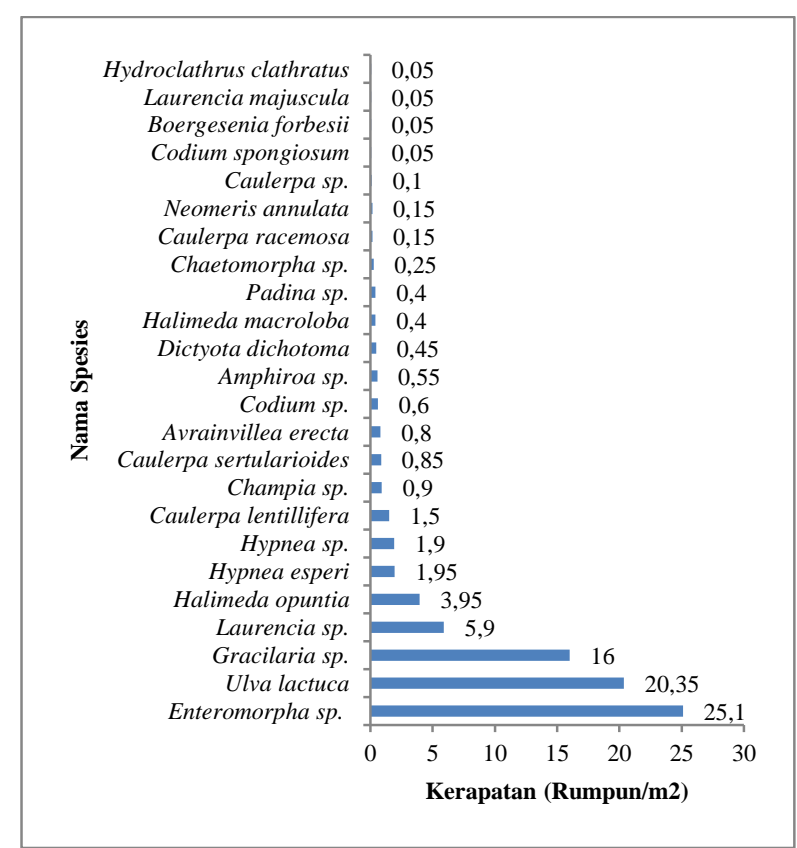

Gambar 3 Kerapatan Setiap Spesies Rumput Laut di Pantai Cemara, Lombok Timur

Nilai penting spesies rumput laut di Pantai Cemara cukup bervariasi. Nilai penting menunjukkan dominansi atau pentingnya kedudukan suatu spesies dalam komunitas. Tiga spesies rumput laut yang memiliki nilai penting tertinggi, secara berurutan, adalah Ulva lactuca, Enteromorpha sp. dan Gracilaria sp., dengan nilai penting berturut-turut $72,69 \%$, 66,55\%, dan 54,05\%. Sedangkan, spesies yang memiliki nilai penting terendah adalah Borgesenia forbesii dan Hydroclathrus clathratus, yaitu $0,93 \%$ (Gambar 4). Berdasarkan hasil tersebut dapat diketahui bahwa spesies yang mendominasi adalah Ulva lactuca. Besarnya nilai penting dipengaruhi oleh nilai ketiga komponen, yaitu frekuensi relatif (FR), kerapatan relatif (KR), dan dominansi relatif (DR). Meskipun memiliki kerapatan tertinggi, Enteromorpha sp. memiliki nilai penting yang lebih rendah dibandingkan Ulva lactuca. Hal tersebut disebabkan karena morfologiUlva lactuca yang berbentuk lembaran dan lebar, sementara Enteromorpha sp. memiliki thalus yang berbentuk tabung memanjangsehingga berpengaruh terhadap luas substrat yang ditutupi. Sebagaimana yang dinyatakan oleh Ameilda et al. (2016) bahwa yang mempengaruhi tutupan makroalga selain kerapatan jenis adalah tipe morfologi spesies alga.

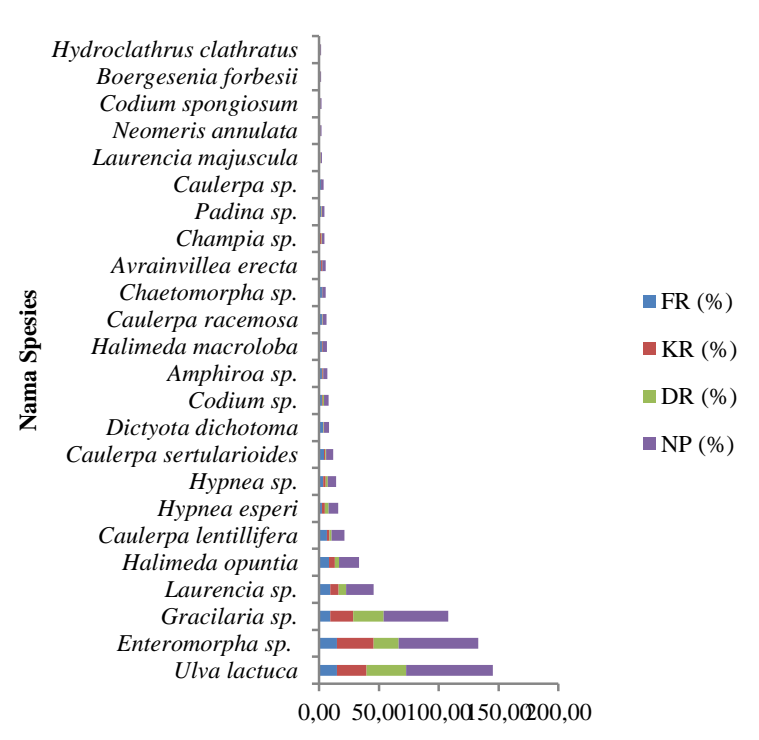

Gambar 4 Proporsi Nilai Frekuensi Relatif, Kerapatan Relatif, Dominansi Relatif, dan Nilai Penting Spesies Rumput Laut di Pantai Cemara, Lombok Timur

Ulva spp. dan Enteromorpha sp. merupakan spesies pioner. Menurut Hatta (1991), dalam proses suksesi ini dikenal dua tipe kelompok alga, yaitu alga primer dan alga sekunder. Kelompok algae primer memiliki aktifitas fotosintesis yang tinggi, pertumbuhan cepat, reproduksi tinggi, struktur tubuh sederhana, dan kebanyakan membentuk rumpun. Alga primerakan selalu tampil sebagai pemegang atau yang dominan dalam tahap awal proses suksesi dan perebutan ruangan diantara jenis alga, sehingga alga primer disebut alga oportunis. Di samping itu, kondisi habitat sangat menentukan keberadaan jenis-jenis algae primer ini.

Indeks keanekaragaman dan indeks kemerataan spesies rumput laut pada keempat transek pengamatan tidak jauh berbeda (Gambar 5). Hal ini bisa jadi dikarenakan faktor lingkungan (suhu, salinitas, dan $\mathrm{pH}$ ) pada keempat transek yang juga relatif sama (Tabel 2). Indeks keanekaragaman spesies di Pantai Cemara berkisar antara 1,695 - 1,973, dengan indeks keanekaragaman secara keseluruhan, yaitu 1,868.Indeks keanekaragaman spesies ( $\left.\mathrm{H}^{\prime}\right)$ tertinggi dari keempat transek pengamatan terdapat di transek II, yaitu 1,973 dan indeks keanekaragaman spesies terendah terdapat di transek I, yaitu 1,695. Berdasarkan ketentuan Shannon-Wiener (dalam Fachrul, 2007), jika nilai $\mathrm{H}^{\prime}>3$, maka keanekaragaman spesies tergolong tinggi, sedangkan jika nilai $1 \leq \mathrm{H}^{\prime} \leq 3$, maka keanekaragaman spesies tergolong sedang, dan jika nilai $H^{\prime}<1$, maka keanekaragaman spesies tergolong rendah, jadi keanekaragaman spesies rumput laut di Pantai Cemara termasuk kategori sedang. Indeks keanekaragaman spesies di Pantai Cemara lebih rendah dibandingkan dengan indeks keanekaragaman spesies di Pantai Jumiang dengan jumlah spesies yang sama (24 spesies), yaitu 2,84 (Zainuddin, 2011) dan di perairan 
Pantai Jikumerasa (21 spesies), yaitu 2,716-2,978 dan indeks kemerataan spesies tinggi, yaitu0.9754 0.9796(Arfah dan Patty, 2016).

Nilai indeks keanekaragaman spesies tergantung dari kekayaan spesies dan kemerataan spesies. Apabila kekayaan spesies bertambah, maka keanekaragamannya akan meningkat dan apabila spesies-spesies mempunyai distribusi kepadatan yang sama maka keanekaragamannya juga akan meningkat (Suheriyanto, 2008 dalam Zainuddin, 2011).

Indeks kemerataan spesies (E) di Pantai Cemaraberkisar antara 0,626 - 0,737, dengan indeks kemerataan secara keseluruhan yaitu 0,699. Jika E = 0 , maka kemerataan antara spesies rendah, dan jika $\mathrm{E}$ $=1$, maka persebaran spesies tinggi/merata (Fachrul, 2007). Dengan demikian, persebaran spesies makroalga di Pantai Cemara hampir merata. Indeks kemerataan tertinggi terdapat di transek III, yaitu 0,737, dan indeks kemerataan terendah terdapat di transek I, yaitu 0,626 .

Meskipun keanekaragaman tertinggi terdapat di transek II, tetapi indeks kemerataanspesies tertinggi terdapat di transek III, yaitu 0,737, dan indeks kemerataan spesies terendah terdapat di transek I, yaitu 0,626. Rendahnya indeks keanekaragaman dan kemerataan spesies pada transek I disebabkan karena adanya spesies yang mendominasi atau jumlah rumpunnya jauh berbeda dengan jumlah rumpun spesies yang lain.

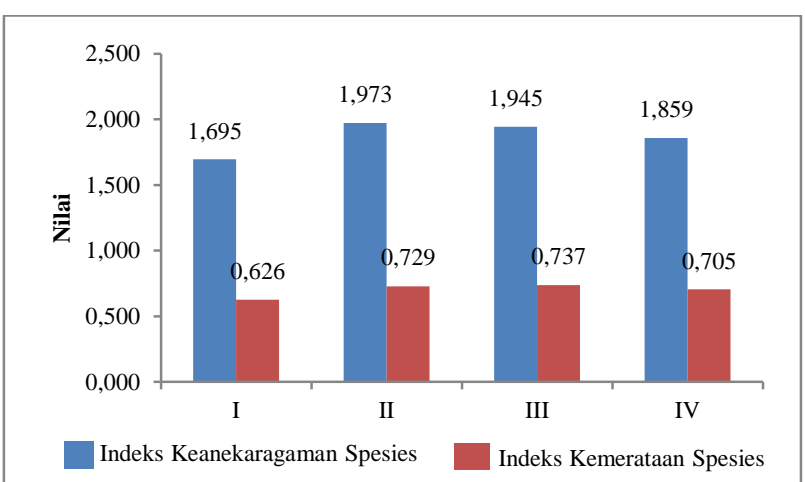

Gambar 5 Perbandingan Indeks Keanekaragaman (H') dan Indeks Kemerataan Spesies (E) Rumput Laut Pada Keempat Transek

Rentang persentase kemiripan berdasarkan parameter lingkungan, kesamaan spesies dan jumlah rumpun spesies rumput laut, indeks keanekaragaman spesies, dan indeks kemerataan spesies berkisar antara $53,68 \%$ - 81,14\%. Persentase kemiripan tertinggi terdapat antara transek II dan IV, yaitu 81,14\%. Transek III terhubung dengan transek II dan IV dengan persentase kemiripan 76,22\%, dan persentase kemiripan terendah tetap terdapat antara transek I dengan transek II, IV, dan III, yaitu 53,68\% (Gambar 6). Dengan memotong garis antara $53,68 \%$ dan $76,22 \%$, maka keempat transek tersebut dikelompokkan menjadi 2, yaitu kelompok pertama terdiri dari transek II, IV, dan III, sementara transek I menjadi kelompok tersendiri berdasarkan kondisi substratnya, dimana transek II, IV, dan III memiliki kondisi substrat yang relatif sama, sementara transek I kondisinya sedikit berbeda.

Rendahnya persentase kesamaan antara transek I dengan transek II, IV, dan III disebabkan karena di samping perbedaan data kondisi lingkungan, indeks keanekaragaman, dan indeks kemerataan, data jumlah rumpun spesies pada transek I juga sangat jauh berbeda dengan yang terdapat pada tiga transek lainnya.Perbedaan variasi substrat diduga menjadi penyebab jauhnya kemiripan antara transek I dengan yang lain.

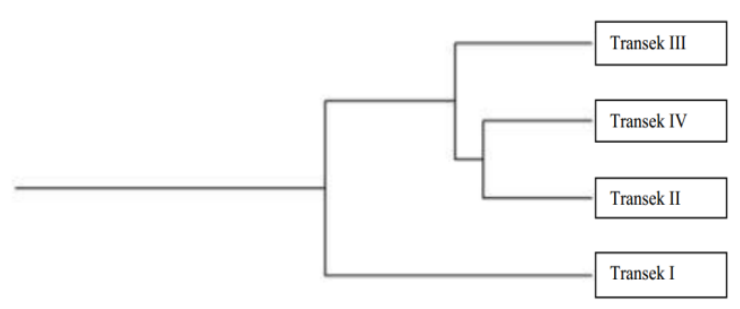

Gambar 6 Persentase Kemiripan antar Transek PengamatanRumput Laut di Pantai Cemara, Lombok Timur

\section{Kesimpulan}

Komunitas rumput laut (makroalga) di Pantai Cemara terdiri dari 24 spesies yang dikelompokkan ke dalam 3 divisi, dimana 14 spesiesnya merupakan divisi Chlorophyta, 7 spesies divisi Rhodophyta, dan 3 spesies divisi Phaeophyta. Kerapatan rata-rata rumput laut di Pantai Cemara, yaitu 3,44 rumpun $/ \mathrm{m}^{2}$. Spesies yang memiliki kerapatan tertinggi adalah Enteromorpha sp., yaitu $25,1 \mathrm{rumpun} / \mathrm{m}^{2}$, dan spesies dengan nilai penting tertinggi adalah Ulva lactuca, yaitu 72,69\%.Secara keseluruhan, keanekaragaman makroalga di Pantai Cemara tergolong sedang, dengan indeks keanekaragaman spesies 1,868 dan indeks kemerataan spesies yaitu 0,699 yang berarti penyebaran spesies hampir merata.

\section{Referensi}

Al-Yamani, F.Y., I. Polikarpov, A. Al-Ghunaim \& T. Mikhaylova (2014). Field Guide of Marine Macroalgae (Chlorophyta, Rhodophyta, Phaeophyceae) of Kuwait. Kuwait: Kuwait Instiute for Scientific Research.

Ameilda, C.H., I. Dewiyanti \& C. Octavina (2016). Struktur Komunitas Perifiton Pada Makroalga Ulva Lactuca di Perairan Pantai Ulee Lheue, Banda Aceh. Jurnal Ilmiah Mahasiswa Kelautan Dan Perikanan Unsyiah.1(3): 337347. http://jim.unsyiah.ac.id/fkp/article/view/1607 
Arfah, H. \& S.I. Patty (2016). Water Quality And Community Macroalgae In Jikumerasa Coastal Waters, Buru Island. Jurnal Ilmiah platax.4(2): 109-119.

https://ejournal.unsrat.ac.id/index.php/platax/a rticle/view/14132

Ate, J.N.B., J.F. da Costa \& T.P.E. Sanubari (2017). Analisis Kandungan Nutrisi Gracilaria Edule (S. G. Gmelin) P. C. Silva dan Gracilaria coronopifolia J. Agardh untuk Pengembangan Perekonomian Masyarakat Pesisir. Jurnal Ilmu Kesehatan. $\quad$ 5(2): 94-103. http://journals.umkt.ac.id/index.php/jik/article /view/57

Atmadja, W.S. (2004). Kolonisasi dan Suksesi Pada Algae Laut Bentik. Oseana. 11(1): 1-10. http://www.oseanografi.lipi.go.id/dokumen/os $\underline{\text { eana xi(1)1-10.pdf }}$

Ayhuan, H.V., N.P. Zamani \& D. Soedharma (2017). Analisis Struktur Komunitas Makroalga Ekonomis Penting di Perairan Intertidal Manokwari, Papua Barat. Jurnal Teknologi Perikanan dan Kelautan. 8(1): 19-38. https://journal.ipb.ac.id/index.php/jtpk/article/ view/17104

Dahuri, R. (2003). Keanekaragaman Hayati Laut, Aset Pembangunan Berkelanjutan Indonesia. Jakarta: PT. Gramedia Pustaka Utama.

Dwimayasanti, R. \& D. Kurnianto (2018). Komunitas Makroalga di Perairan Tayando-Tam, Maluku Tenggara. Oseanologi dan Limnologi di Indonesia. $\quad 3(1)$ : 39-48. https://oldi.lipi.go.id/index.php/oldi/article/vie $\underline{\mathrm{w} / 82 / 0}$

Fachrul, M.F. (2007). Metode Sampling Bioekologi. Jakarta: Bumi Aksara.

Ferawati, E., D.S. Widyartini \& I. Insan (2014). Studi Komunitas Rumput Laut Pada Berbagai Substrat di Perairan Pantai Permisan Kabupaten Cilacap. Scripta Biologica. 1(1): 55-60.

http://journal.bio.unsoed.ac.id/index.php/scrib io/article/view/25

Fuhrer, B., I.G. Christianson, M.N. Clayton \& B.M. Allender (1988). Seaweeds of Australia. Sydney: Reed.

Haryati (2003). Komunitas Makroalga di Derah Intertidal Perairan Pantai Senggigi Lombok Barat Nusa Tenggara Barat. Skripsi. S1 Pendidikan Biologi. FKIP Universitas Mataram, Mataram.
Hatta, A.M. (1991). Beberapa Aspek Interaksi Antara Herbivor dengan Makroalgae di Perairan Tropis (Indonesia dan Sekitarnya). Oseana.16(2): 1-20. http://oseanografi.lipi.go.id/dokumen/oseana $\underline{\text { xvi(2)1-20.pdf }}$

Herlinawati, N.D.P.D., IW. Arthana \& A.P.W.K. Dewi (2017). Keanekaragaman dan Kerapatan Rumput Laut Alami Perairan Pulau Serangan Denpasar Bali. Journal of Marine and Aquatic Sciences. $\quad 4(1): \quad 22-30$. https://ojs.unud.ac.id/index.php/jmas/article/vi ew/33036

Ira (2018). Struktur Komunitas Makro Alga di Perairan Desa Mata Sulawesi Tenggara. Jurnal Biologi Tropis. 18(1): 45-56. https://jurnalfkip.unram.ac.id/index.php/JBT/a $\underline{\text { rticle/view/729 }}$

Jha, B., C.R.K. Reddy, M.C. Thakur \& M.U. Rao (2009). Seaweeds of India: The Diversity and Distribution of Seaweeds of the Gujarat Coast. New York: Springer Dordrecht Heidelberg. https://books.google.co.id/books?hl=id\&lr=\&i $\mathrm{d}=\mathrm{jOG} 4 \mathrm{kC} 5 \mathrm{qtqMC} \&$ oi $=$ fnd $\& \mathrm{pg}=\mathrm{PA} 2 \& \mathrm{dq}=\mathrm{Jh}$ a,+B.,+C.R.K.+Reddy,+M.C.+Thakur

Karnan, D. Santoso, L. Japa \& A. Raksun (2018). Makroalga di Daerah Intertidal Pulau Lombok Bagian Selatan. Jurnal Biologi Tropis.18(1): 109-121.

http://www.jurnalfkip.unram.ac.id/index.php/J BT/article/view/738

Kasim, M. (2016). Makroalga: Kajian Biologi, Ekologi, Pemanfaatan, dan Budidaya. Jakarta: Penerbit Swadaya.

Kuncoro, E.B. (2004). Akuarium Laut. Yogyakarta: Kanisius.

https://books.google.co.id/books?hl=id\&lr=\&i $\mathrm{d}=$ hbHafEkjXQoC\&oi=fnd\&pg=PA17\&dq= Kuncoro,+E.B.+(2004).

Kurniawan, R. (2017). Keanekaragaman Jenis Makroalga di Perairan Laut Desa Teluk Bakau Kabupaten Bintan Kepulauan Riau. Skripsi. Jurusan Ilmu Kelautan Fakultas Ilmu Kelautan Dan Perikanan Universitas Maritim Raja Ali Haji, Tanjung Pinang.

Luthfi, O.M. \& A. Jauhari (2013). Assesmen Kondisi Fisika-Kimia Oseanografi Perairan Pulau Sempu Malang Selatan sebagai Parameter Penentuan Lokasi Pembuatan Taman Karang. Prosiding PIT ISOI.

Palallo, A. (2013). Distribusi Makroalga Pada Ekosistem Lamun Dan 
Terumbu Karang di Pulau Bonebatang, KecamatanUjung Tanah, Kelurahan Barrang Lompo, Makassar. Skripsi. Program Studi Ilmu Kelautan. Fakultas Ilmu Kelautan dan Perikanan Universitas Hasanuddin, Makassar.

Romimohtarto, K. \& S. Juwana (2007). Biologi Laut. Jakarta: Djambatan.

Salim, Z. \& Ernawati (2015). Info Komoditi Rumput Laut. Jakarta: AMP Press.

Sari, S.M. Produksi Rumput Laut (2017) Turun.http://industri.bisnis.com/read/2018020 6/99/735329/produksi-rumput-laut-2017turun. Diakses tanggal 30 Mei 2018 pukul 10:30 WITA.

Sinyo, Y. \& N. Somadayo (2013). Studi Keanekaragaman Jenis Makroalga di Perairan Pantai Pulau Dofamuel Sidangoli Kecamatan Jailolo Selatan Kabupaten Halmahera Barat. Jurnal Bioedukasi.1(2): 120-130.
Sukiman, A. Muspiah, S.P. Astuti, H. Ahyadi \& E. Aryanti (2014). Keanekaragaman dan Distribusi Spesies Makroalga di Wilayah Sekotong Lombok Barat. Jurnal Penelitian UNRAM. 18(2): 71-81.

Supriati, R. (2003). Keanekaragaman, Kepadatan, dan Pola Penyebaran Makroalga di Pantai Panjang Kota Bengkulu. Skripsi. FMIPA Universitas Sriwijaya.

Wibowo, S., R. Peranginangin, M. Darmawan \& A.R. Hakim (2014). Teknik Pengolahan ATC Dari Rumput Laut Eucheuma Cottonii. Jakarta: Penebar Swadaya. https://books.google.co.id/books?hl=id\&lr=\&i $\mathrm{d}=6 \mathrm{DWqCgAAQBAJ} \&$ oi $=$ fnd $\& p g=P P 1 \& d q=$ Wibowo,

Zainuddin (2011). Studi Keanekaragaman Makroalga di Pantai Jumiang Kabupaten Pamekasan. Skripsi. S1 Biologi. Fakultas Sains dan Teknologi Universitas Islam Negeri Maulana Malik Ibrahim. 